\title{
A FORMAÇÃO DO EDUCADOR AMBIENTAL EM DEBATE: UMA PERSPECTIVA INTERDISCIPLINAR SOBRE O PERFIL DESTE PROFISSIONAL
}

\author{
Valéria Sousa Duarte ${ }^{1}$ \\ Maria do Rosário Knechtel ${ }^{2}$ \\ Eloisa Beling Loose ${ }^{3}$ \\ Joyde Giacomini Martínez ${ }^{4}$ \\ Livia Priori Gonçalves ${ }^{5}$ \\ Renata Brockelt Giacomitti ${ }^{6}$
}

Resumo: A partir de leituras e discussões sobre os significados da crítica ao profissionalismo, da importância da criatividade no processo educativo e de diferentes abordagens sobre a educação ambiental, este texto busca discutir a necessidade e o público da formação de educadores ambientais. As autoras deste trabalho provêm de campos de conhecimentos diferentes, mas encontram, na interface entre educação e meio ambiente, um ponto comum que lhes motiva a pensar sobre quem pode e deve trabalhar com a educação ambiental, assim como quais os aspectos que devem ser considerados e incorporados nesse processo. Ao final, propõem-se princípios para uma educação ambiental transformadora, que modifique, de fato, a perspectiva dos indivíduos em relação com o meio que os cerca.

Palavras-chave: Formação de educadores. Princípios da educação ambiental. Educação ambiental.

\footnotetext{
${ }^{1}$ Mestre em Meio Ambiente e Desenvolvimento pela Universidade Federal do Paraná (UFPR). Pesquisadora do Grupo "Comunicação e Educação em diversas interfaces com ênfase em meio ambiente" da UFPR. duarteval@gmail.com

${ }^{2}$ Doutora em Sociologia da Educação pela Universidade Federal de Santa Maria (UFSM). Docente do Programa de Pós-Graduação em Meio Ambiente e Desenvolvimento da Universidade Federal do Paraná (UFPR). mknechtel10@gmail.com

${ }^{3}$ Mestre em Comunicação e Informação pela Universidade Federal do Rio Grande do Sul (UFRGS). Doutoranda em Meio Ambiente e Desenvolvimento pela Universidade Federal do Paraná (UFPR). Bolsista CNPq. eloisa.loose@gmail.com

${ }^{4}$ Mestre em Ciências Ambientais pela Universidade do Extremo Sul Catarinense (UNESC). Doutoranda em Meio Ambiente e Desenvolvimento pela Universidade Federal do Paraná (UFPR). Bolsista CNPq. joydegm@gmail.com

${ }^{5}$ Bióloga pela Universidade Federal do Paraná (UFPR). MBA internacional em Gestão Ambiental em andamento pela UFPR. livia.priori@gmail.com

${ }^{6}$ Mestre em Meio Ambiente e Desenvolvimento pela Universidade Federal do Paraná (UFPR). Analista na assessoria jurídica da Capitania dos Portos do Paraná (Marinha do Brasil). renatagiacomitti@gmail.com
} 


\section{ENVIRONMENTAL EDUCATORS, TRAINING IN DEBATE: AN INTERDISCIPLINARY PERSPECTIVE ABOUT THIS PROFESSIONAL'S PROFILE}

Abstract: From readings and discussions about the meanings of the critique of professionalism, the importance of creativity in the educational process and the different approaches to environmental education, this paper aims to discuss the need and the audience of environmental educators' training. The authors of this essay come from different fields of knowledge, and it is at the interface between education and the environment that resides a common point that motivates them to think about who can and should work with environmental education, as well as which aspects should be considered and incorporated in this process. Finally, principles are proposed for a transformative environmental education, in order to actually modify the perspective of individuals in regard of their surroundings.

Keywords: Educators' training. Environmental education principles. Environmental education.

\section{LA FORMACIÓN DE LOS EDUCADORES AMBIENTALES EN DEBATE: UNA PERSPECTIVA INTERDISCIPLINARIA SOBRE EL PERFIL DE ESTE PROFESIONAL}

Resumen: A partir de las lecturas y discusiones sobre los significados de la crítica a la profesionalidad, la importancia de la creatividad en el proceso educativo y los diferentes enfoques de la educación ambiental, el presente trabajo pretende discutir la necesidad y el público de la formación de los educadores ambientales. Las autoras de este trabajo son de diferentes campos del conocimiento, pero se ubican entre la educación y el medio ambiente, punto común que las motiva a pensar sobre quienes pueden y deben trabajar con la educación ambiental, así como qué aspectos deben ser considerados e incorporados en este proceso. Al final, se propone principios para una educación ambiental transformadora, que modifica, de hecho, la perspectiva de los individuos en relación con su entorno.

Palabras clave: Formación de educadores. Principios de la educación ambiental. Educación ambiental.

\section{Introdução}

O interesse por discutir e refletir as questões relacionadas à formação de educadores ambientais une as cinco autoras deste texto, oriundas dos campos da Biologia, Comunicação e Direito, na prática interdisciplinar da construção de conhecimento, com base em diálogo de saberes e dinâmicas interativas no coletivo. Estas, inseridas no contexto do Programa de Pós-Graduação em Meio Ambiente e Desenvolvimento da Universidade Federal do Paraná (PPGMADE/UFPR), e instigadas pela interface entre educação e meio ambiente, questionaram-se sobre o seu fazer enquanto profissionais engajadas com a 
educação ambiental, assim como com os fundamentos de uma formação que possibilite a mudança de atitudes. A partir de leituras sobre a criatividade e a inovação (DITTRICH, 2011), o profissionalismo e o fim da autenticidade (BALL, 2012), a perspectiva da educação ambiental e o multiculturalismo como campos de coexistência frente às novas racionalidades socioambientais (SOUZA-LIMA; KNECHTEL, 2012) e a formação do profissional educador ambiental (MORALES, 2012) objetiva-se, neste artigo, tratar da relação entre a educação ambiental e o processo de aprendizado de quem a faz.

A compreensão de que uma formação para a educação ambiental ultrapassa a conquista de um diploma acadêmico, necessitando, também, de atualização constante, exercício de práticas pedagógicas inovadoras, conhecimento e abertura para o fazer interdisciplinar, além da perspectiva de que as relações sociedade-natureza são complexas e não devem ser reduzidas a projetos pontuais e sem continuidade, faz emergir uma série de questionamentos sobre o que esta representa e como é pensada. A tentativa deste trabalho é debater sobre quem está preparado para ser educador ambiental, qual a relevância desse profissional e quais seriam os pressupostos essenciais dessa formação.

Para tanto, o texto foi organizado em quatro partes. A primeira se detém em uma discussão conceitual sobre formação de educadores ambientais e o próprio entendimento de educação ambiental; a segunda busca responder as inquietações das autoras sobre a razão de formar educadores ambientais e o perfil dos profissionais que requereriam tal formação; na terceira apontam-se algumas considerações, de caráter propositivo, sobre o que não poderia faltar nessa formação e a quem ela deveria servir imediatamente, considerando que estamos diante de uma crise socioambiental que precisa ser urgentemente enfrentada; e, por fim, expõem-se correntes da educação ambiental afins com os fundamentos considerados básicos.

Cabe salientar que se compreende, aqui, o conceito de formação como aquele "processo permanente e reflexivo, em que o significado de formar não está vinculado à ação de dar ou tomar forma (...) [e sim ao] processo reflexivo de reorganização do saber frente à intervenção na transformação da realidade" (MORALES, 2012, p.24), o que permite que a percebamos para além da educação ambiental formal. Também se ressalta, nesta introdução, a ideia de educação ambiental sobre a qual se fundamenta o debate, construída por Floriani e Knechtel (2003, p.56), que "propõe a construção do conhecimento da educação socialmente crítica, baseada em novas racionalidades de saberes em um processo de análise das realidades ambientais, sociais e educativas inter-relacionadas, com a finalidade de transformá-las".

Desse modo, pensando que a educação ambiental possui esse potencial de modificar as ações das pessoas em prol de um mundo, de fato, sustentável, acredita-se ser importante perceber como o sujeito articula seus saberes no ato de educar. A discussão sobre como se dá a formação de educadores ambientais que realmente transformem visões de mundo em função da frágil e complexa relação sociedade-natureza é o ponto central deste texto.

\section{Educação ambiental: os conceitos e seus sujeitos}

Antes de se adentrar na questão de quem são os sujeitos que trabalham com a educação ambiental, faz-se necessária, ainda que de forma breve, uma apresentação 
reflexiva sobre seu conceito. A educação ambiental é entendida como uma modalidade da educação permanente (KNECHTEL, 2001), tendo esta última o sentido de aprendizado constante, no qual a educação se apresenta em evolução desde o nascimento ao desaparecimento dos sujeitos.

Knechtel (2001) discorreu sobre o tema, definindo-a como um conjunto de modalidades de desenvolvimento do saber elaborado, como forma de manifestação de todo ato humano. Para a autora, as bases da educação permanente foram iniciadas por Rousseau e Kant, que preconizavam uma educação integral, total e humana. Argumenta que esses princípios pregam a transformação de homens e mulheres "em cidadãos do mundo, pessoas responsáveis e autônomas que ao se formarem e aprimorarem, formam, reformam e aprimoram o mundo em que vivem" (KNECHTEL, 2001, p.81-82).

Assim, é enfatizado que, dentro dos pressupostos iniciais da educação permanente, deve ocorrer a formação de formadores de adultos para que estes, se tornando iluminadores, possam auxiliar na construção conjunta do saber, de forma a permitir uma emancipação psicológica e social de todos os cidadãos. É importante que se perceba como o conceito de educação permanente é mais abrangente do que o de educação ambiental, no sentido de que aquele fomenta uma relação dialética entre o homem e a sociedade onde a relação se estabelece, garantindo ao homem seu enraizamento nos meios em que se integra.

Partindo da compreensão de que toda educação ambiental deve ser permanente, elencam-se algumas definições que auxiliam na compreensão da abrangência do conceito. Reigota (2001, p.10) traz um esclarecimento sobre as dimensões que estão vinculadas à expressão:

[...] a educação ambiental deve ser entendida como educação política, no sentido de que ela reivindica e prepara os cidadãos para exigir justiça social, cidadania nacional e planetária, autogestão e ética nas relações sociais e com a natureza. A educação ambiental como educação política enfatiza antes a questão 'por que' fazer do que 'como' fazer. Considerando que a educação ambiental surge e se consolida num momento histórico de grandes mudanças no mundo ela tende a questionar as opções atuais e o próprio conceito de educação vigente, exigindo-a, por princípio, criativa, inovadora e crítica.

Na mesma linha, Floriani e Knechtel (2003, p.50) conceituam educação ambiental como sendo "um componente nodal e não um simples acessório da educação, já que envolve a reconstrução do sistema de relações entre pessoas, sociedade e ambiente". Ou seja, a educação ambiental é vista como um elemento que une e articula diferentes âmbitos do conhecimento e também das práticas cotidianas.

Em âmbito internacional, talvez a mais relevante contribuição para a construção do conceito de educação ambiental seja aquela extraída das recomendações da Conferência de Tbilisi (1977). O documento afirma que a educação ambiental "é o resultado de uma reorientação e articulação de diversas disciplinas e experiências educativas que facilitam a percepção integrada do meio ambiente" (UNESCO, 1980, p 73.). No Brasil, o marco legal que regulamenta a questão é o conceito encontrado na Lei $\mathrm{n}^{\circ} 9.795 / 1999$, em seu artigo $1^{\circ}$ :

Entende-se por educação ambiental os processos por meio dos quais o indivíduo e a coletividade constroem valores sociais, conhecimentos, habilidades, atitudes e competências voltadas para a conservação do meio ambiente, bem de uso comum 
do povo, essencial à sadia qualidade de vida e sua sustentabilidade (BRASIL, $1999, \mathrm{~s} / \mathrm{p})$.

A partir dessas concepções, é perceptível que a formação de sujeitos para a realização da educação ambiental implica no domínio de conhecimentos abrangentes, a sensibilidade para trabalhar com temas complexos e transversais, e a disponibilidade para o diálogo aberto e crítico sobre as relações dos homens com o meio ambiente. Tal atividade não cessa nos esforços em sala de aula, precisando estar presente nos diferentes setores da sociedade e sublinhando a ideia de que a educação ambiental é, também, uma modalidade de educação permanente.

Percebe-se, então, que a educação ambiental é vista como uma forma de despertar o indivíduo para sua responsabilidade social. Isso se dá através de uma conscientização pessoal e por intermédio de um educador, de forma a resultar na compreensão do motivo pelo qual é necessária a ocorrência de mudanças em seus padrões sociais e de comportamento individual. A educação ambiental defendida neste artigo extrapola os espaços institucionalizados de educação e projetos pontuais, assim como visões fragmentadas e reducionistas sobre os temas ambientais. Logo, a formação de profissionais (ou educadores ambientais) que possa levar a concepções mais abrangentes e que realmente causem mudanças nos modos de ser e fazer da sociedade é calcada nessa perspectiva mais crítica, de caráter mobilizador e transformador.

Ressalta-se que a multiplicidade de correntes da educação ambiental encontrada na literatura da área não é ignorada, e é abordada, oportunamente, mais adiante. Contudo, acredita-se que muitos pontos fundamentais da formação de educadores ambientais coexistem em várias correntes ou são enfatizados em diferentes graus conforme a perspectiva adotada. Portanto, optou-se por definir princípios que não poderiam estar descolados da formação de um educador ambiental que busque a autenticidade e a transformação sob o viés ambiental, seja qual for a corrente adotada.

Antes de se abordar essa perspectiva com maior profundidade, apresenta-se quem seriam os profissionais habilitados a trabalhar com educação e meio ambiente segundo a legislação brasileira. Tal recorte introduz o debate sobre quem deveria ser ou estaria apto a ser o profissional da educação ambiental.

\subsection{Profissionais da educação e do meio ambiente}

Segundo a Lei nº 9.394/96, de Diretrizes e Bases da Educação Nacional (LDB), a educação abrange não apenas o aspecto escolar, mas os processos formativos ocorridos no âmbito familiar, na convivência humana, no trabalho, em instituições de ensino e pesquisa, organizações da sociedade civil (como movimentos sociais) e em manifestações culturais (BRASIL, 1996). Essa acepção permite inferir que toda a população é composta de educadores e educandos, capazes de aprender e ensinar dialogicamente em todas as suas esferas de vida. Entretanto, a modalidade escolar se mantém, ao longo do tempo, como base fundamental da educação, motivo pelo qual se indaga: os profissionais da área educacional estariam automaticamente aptos a serem educadores ambientais?

Para dar início a essa discussão, primeiramente é necessário definir quem são esses sujeitos. O artigo 62 da LDB/1996 considera como profissionais da educação tanto os 
indivíduos atuantes no magistério quanto em funções pedagógico-administrativas da educação básica, e essa será a delimitação da categoria utilizada daqui por diante. Isso significa que profissionais ligados à área de meio ambiente que atendam a esses prérequisitos podem carregar consigo o título de profissionais da educação. Porém, a categoria não se limita à última área, sendo também composta por profissionais da área ambiental sem conhecimentos atrelados à educação. Cabe, assim, uma breve discussão conceitual do que se entende por meio ambiente.

A Declaração da Conferência da Organização das Nações Unidas (ONU) sobre Meio Ambiente realizada em Estocolmo (1972) aponta para uma visão de meio ambiente que vai além do meio natural, levando em conta os aspectos socioculturais:

O homem é ao mesmo tempo obra e construtor do meio ambiente que o cerca, o qual lhe dá sustento material e lhe oferece oportunidade para desenvolver-se intelectual, moral, social e espiritualmente. (...) Os dois aspectos do meio ambiente humano, o natural e o artificial, são essenciais para o bem-estar do homem e para o gozo dos direitos humanos fundamentais, inclusive o direito à vida mesma (ONU, 1972, s/p).

Com uma visão mais restrita, a Lei $\mathrm{n}^{\circ}$. 6.938/1981, que dispõe sobre a Política Nacional do Meio Ambiente, através do art. $3^{\circ}$, I, apresenta uma definição bem objetiva a respeito do meio ambiente, como sendo "o conjunto de condições, leis, influências e interações de ordem física, química e biológica, que permite, abriga e rege a vida em todas as suas formas" (BRASIL, 1981). Já a que institui a Política Nacional de Educação Ambiental ( $\mathrm{n}^{\circ}$. 9.793/1999), apresenta como um dos princípios básicos da educação ambiental a concepção do meio ambiente em sua totalidade, considerando a interdependência entre o meio natural, o socioeconômico e o cultural, sob o enfoque da sustentabilidade (BRASIL, 1999).

A partir dessa breve revisão de como a legislação brasileira enquadra a questão ambiental e como, em geral, não define os profissionais responsáveis por suas questões, observa-se a relevância da compreensão de meio ambiente daqueles sujeitos que trabalharão na área. Levando em conta que no meio corporativo a educação ambiental tem grande relevância na gestão, minimizando impactos ambientais negativos por meio de seus princípios e aplicações práticas (SALES; CANTARINO, 2011), cabe levantar a seguinte questão: estariam os profissionais de meio ambiente aptos a trabalhar com educação ambiental? E quanto aos da educação? Quem seria o profissional ideal para formar e/ou educar ambientalmente?

Considerando-se ainda que a LDB/1996 aponta os princípios pelos quais o ensino deve ser ministrado, é imperativo refletir a respeito do que é encontrado na teoria versus o que se percebe no dia-a-dia, além de analisá-los paralelamente aos princípios da educação ambiental almejada. Segundo essa lei, a educação deve ser pautada em doze princípios básicos, dos quais se destacam a liberdade, respeito e pluralismo de saberes, pensamentos e aprendizagens; a valorização da experiência extraescolar; e o estabelecimento de vínculos entre a educação escolar, trabalho e práticas sociais. Contudo, tais aspectos nem sempre conseguem ser seguidos pelos profissionais da educação, já que o profissionalismo vigente (BALL, 2012) restringe o ato de educar às demandas postas por sistemas de ensino focados unicamente em aprovação e boas notas. Assim, as amarras postas por instituições 
direcionadas ao produtivismo e à busca por resultados que possam ser mensuráveis (para alcançar posições em rankings quantitativos de bom desempenho) sobrepõem-se à formação plural e abrangente condizente com a perspectiva da educação ambiental.

Outro ponto atrelado a esta discussão está no fato de que a didática presente na formação dos profissionais da educação não costuma aparecer na formação de profissionais de meio ambiente, assim como conhecimentos específicos da área ambiental não fazem parte da formação dos profissionais da educação. Logo, a partir de um primeiro olhar, nenhuma das duas formações seria suficiente para dar conta da atribuição complexa que compete ao educador ambiental. Uma situação ideal seria realizar o trabalho com uma equipe interdisciplinar, envolvendo profissionais de várias áreas, porém com visões de mundo que abarquem as conexões entre natureza e sociedade de forma responsável e autêntica.

É importante mencionar que existem cursos, como os de especialização na área, que podem contribuir para a formação dos profissionais que se debruçam sobre esse desafio. Acredita-se que nenhum curso, por si só, possa tornar um sujeito em educador ambiental, visto que todas as graduações apresentam deficiências inerentes nesse sentido. Entretanto, salienta-se que tais oportunidades de qualificação podem ser pontos de partida para uma formação que deve ser permanente e para compreender uma visão de mundo transformadora da relação homem-natureza. De forma complementar à formação disciplinar, os educadores ambientais devem ter uma disposição ao diálogo com outros sujeitos a fim de ampliar e enriquecer suas concepções de mundo.

Diante do que foi posto, entende-se que nem o profissional da educação, nem aquele com conhecimentos ambientais (ou formação técnica na área) estaria, de imediato, pronto para educar ambientalmente de forma ideal. A educação ambiental necessita de sujeitos que possuam características inerentes à formação desses dois profissionais e, mais ainda, precisa ir além, respeitando certos princípios ou fundamentos que considerem aspectos da própria epistemologia ambiental. Para Freire (2003, p.15), mais que ensinar conteúdos, a educação ambiental implica embutir outra postura, revelando que o educador ambiental tem uma tarefa "não somente de natureza epistemológica-cognitiva, mas também ético-políticopedagógica".

Em vista disso, no próximo tópico elencam-se algumas características ou atributos que, de acordo com estas autoras, deveriam constar na formação do educador ambiental para que este possa promover uma educação ambiental crítica ${ }^{7}$, que traga mudanças na sociedade.

7 Para Silva (2007), a educação ambiental crítica nega a oposição entre homem, natureza e sociedade, assim como nega a hierarquização entre essas dimensões da ação humana, ou seja, ao deixar de lado a visão dicotômica entre as ciências naturais e sociais, passa-se a admitir que não é possível haver uma hierarquização ou divisão entre homem/natureza, ou cultura/natureza; admitindo-se, também, a necessidade de pensar o ambiente de maneira integrada, levando ao entendimento de que, além de entender a complexidade da relação homem-natureza, é fundamental ao educador ambiental compreender o mundo através de um pensamento crítico e sistêmico. 
Pesquisa em Educação Ambiental, vol. 9, n. 2 - págs. 98-113, 2014

\section{Alguns elementos cruciais para se tornar um educador ambiental}

A partir do que já foi posto, verifica-se que para assumir e exercer uma educação ambiental qualificada, mais que atender a critérios dados na legislação, ter formação técnica ou específica e realizar cursos que tratem do assunto, o sujeito incumbido de formar e educar com vistas a uma maior consciência ambiental deveria estar atento a alguns elementos ou princípios que cercam o campo de uma educação transformadora.

Além de expor os desafios e complexidades da temática ambiental, é preciso que o educador tenha uma postura diferenciada e integradora do homem e natureza, mostrando que a mobilização social frente às questões ambientais só pode se dar com uma visão de mundo que englobe uma cidadania e ética condizentes com a perspectiva ambiental. Nesse sentido, a partir da literatura da área e dos próprios princípios que se encontram na legislação em vigor, apontam-se alguns tópicos, transversais a várias correntes e referências da área, que seriam fundamentais para a formação de um educador ambiental autêntico. Tais atributos se relacionam e buscam identificar aquele educador ambiental alinhado com a ideia da educação como propulsora de mudanças sociais.

Sob o olhar destas autoras, esses atributos cruciais diriam respeito a:

\section{1) Sensibilidade afetiva e cognitiva}

Carvalho (2008) considera que as características necessárias para uma leitura de mundo do ponto de vista ambiental são, fundamentalmente, a sensibilidade afetiva e capacidade cognitiva do educador. Por meio delas seria possível funcionar como mediador e intérprete de múltiplas compreensões das experiências dos educandos, tanto individual quanto coletivamente, além de permanecer permeável a novos acontecimentos e conhecimentos. Assim, haveria abertura para a problematização dos diferentes interesses com vistas a uma prática reflexiva e participante, sem neutralidade, que culmine em uma cidadania ambientalmente saudável, crítica e responsável.

Isso implicaria, especialmente por parte do educador, em uma postura atenta, curiosa, observadora das variadas relações e dimensões da realidade e construtora de um conhecimento dialógico adequado à complexidade ambiental. A experiência também é requerida, no sentido dado por Gadamer (1998, apud CARVALHO, 2008, p.84), em que alguém experimentado não é somente aquele que se molda por meio de sua bagagem, mas quem se mantém receptivo a novas experiências. "A dialética da experiência tem sua própria consumação não num saber concludente, mas nessa abertura à experiência que é posta em funcionamento pela própria experiência".

Além dessas características, é preciso que o educador não abra mão do que Ball (2012) chamou de autenticidade - isto é, uma prática de ensino com desejo e significado pessoais, capaz de motivar a si mesmo e aos outros. Educadores autênticos seriam aqueles capazes de agir em situações complexas e/ou ambivalentes, onde a incerteza serviria como catalisador de mudanças e da liberdade de pensamento e expressão. Não seriam submissos às exigências descabidas do gerencialismo e performatividade; tratariam de trilhar, ainda que submetidos a regras rígidas, seus próprios caminhos sem sucumbir ao comodismo ou inércia participativa.

\section{2) Criatividade}

Acredita-se que a criatividade seja um elemento crucial para o desenvolvimento de novas práticas e formas de compreensão na área da educação ambiental. A inventividade 
humana está atrelada ao fazer criativo, que muito pode contribuir para a construção de novas experiências e ações em prol das questões emergentes do meio ambiente. Além disso, retomando a perspectiva de Ball (2012), a autenticidade dos sujeitos está intimamente ligada ao investimento que estes dão ao diálogo, à imaginação e à criatividade, mostrandose o processo criativo essencial para escapar das amarras produtivistas na qual estão inseridos os diferentes setores da sociedade - incluindo-se a educação e a sensibilização para a relação com o outro e com o ambiente.

De forma semelhante, Barcelos (2012) critica a educação realizada por meio da competição e não da cooperação. Para esse autor, no confronto com questões ainda novas surge a necessidade de buscar caminhos inovadores e, para tanto, a criação, a invenção, a experiência e a experimentação devem ser consideradas. $O$ cuidado com questões ambientais tem pedido que os modelos pelos quais se pensa e age sejam reavaliados, uma vez que se demonstram cada vez mais insuficientes.

A fim de avançar e tornar a educação ambiental efetiva é preciso que se estabeleçam novas relações entre educador e educando que proporcionem fluxos e/ou perturbações criativos, pois "provocam novas aberturas para novas aprendizagens" (DITTRICH, 2011, p.113). Apoiada em de La Torre (1998), Dittrich (2011, p.113) afirma que, na educação, a inovação "tem um caráter processual pessoal e institucional, dinâmico e aberto, contínuo e adaptativo, pois implica um caminhar construtivo frente aos problemas que vão surgindo na realidade sociocultural". Portanto, na elaboração de um conhecimento aberto, flexível, afetivo e profundamente relacionado com a realidade do educando, a criatividade humana deve estar presente e atuar de maneira transformadora nas visões de mundo hegemônicas.

\section{3) Interdisciplinaridade}

Insiste-se, aqui, no diálogo entre diferentes saberes, visto que a transdisciplinaridade ${ }^{8}$ ainda está muito longe de ser alcançada no cotidiano não apenas das práticas educativas, mas de uma maneira geral. Ao realizar de forma plena a interdisciplinaridade, já se está diante de uma mudança de paradigmas que em muito poderá beneficiar as ações em prol da educação e do meio ambiente. Leff (2001) ao falar da interdisciplinaridade aponta para a necessidade de problematizar e renovar os conhecimentos por meio do saber ambiental e de uma nova racionalidade, de modo a ultrapassar as barreiras disciplinares e proporcionar um diálogo de saberes - uma clara articulação com os objetivos da educação ambiental.

A interdisciplinaridade já é um princípio conhecido por aqueles que se interessam pela educação ambiental, pois critica o modelo de organização e produção de conhecimento da ciência cartesiana, ainda hoje dominante, e a especialização que resulta em sua fragmentação e redução. Alvarenga et al. (2011, p.21) destacam que a religação de saberes traz como objetivo final dar conta de complexidades e fenômenos de diversas naturezas. Já Carneiro et al. (2012, p.91) ressaltam a interdisciplinaridade na formação de educadores ambientais como central, além de constituir prática pedagógica que "propicia a superação da linearidade e da artificialização no processo de produção do conhecimento e no processo

8 Oliveira (2005, p.336) distingue os dois termos: enquanto a interdisciplinaridade gira em torno da relação entre as disciplinas, com seus interesses próprios preservados, a transdisciplinaridade busca superar o conceito de disciplina, "através da intercomunicação entre as disciplinas, tratando de um tema/objetivo/problema comum (transversal)". 
educativo". Para esses autores, a interdisciplinaridade compõe uma dinâmica pedagógica aberta, dialética e reflexiva na inclusão de questões ambientais e multiculturais a fim de valorizar as diferenças e o diálogo de saberes no processo educativo.

4) Domínio de conhecimentos e abertura para o diálogo

Em razão da complexidade inerente aos temas ambientais, a formação de educadores ambientais deve se preocupar, também, com o esclarecimento de conceitos e processos de diferentes áreas do conhecimento. Aliás, este é um pré-requisito básico para que ocorra a interdisciplinaridade. Não é possível buscar o diálogo de saberes sem a mínima compreensão de como o outro percebe o problema e de como pode contribuir para sua resolução. Também, conhecer os limites e fundamentos de cada disciplina passa a ser mais uma forma de reconhecer a necessidade de práticas interdisciplinares.

Logo, para que os educadores ambientais possam dialogar e realizar práticas interdisciplinares inovadoras é preciso que haja certo domínio de conhecimento e de metodologias das outras disciplinas com o objetivo de propiciar condições iniciais para o desenvolvimento de ações integrativas e que expandam os limites disciplinares. Assim, na formação do educador ambiental deve-se, primeiro, se considerar a formação de espíritos esclarecidos "(...) que saibam adotar uma visão global da realidade contemporânea" (RAYNAUT; ZANONI, 2011, p.156).

5) Enfoque complexo, crítico e sistêmico

A educação ambiental frequentemente encontra apoio nas ideias de Morin (2011) e na sua teoria da complexidade como maneira de fundamentação. Dessa forma, os educadores ambientais não devem se esquivar de enxergar o mundo a partir de suas múltiplas conexões, as quais envolvem os polos de individualidade, espécie e ambiente e suas interconexões (SILVA, 2007).

Leff (2001) também concebe a complexidade, porém, segundo Morales (2007), difere da abordagem de Morin (2011) ao considerar que o saber ambiental se forma a partir da construção de uma racionalidade produtiva alternativa pautada num processo político e social, como nova perspectiva de análise das relações entre produção e conhecimento. Nesse sentido, há uma aproximação entre a abordagem de complexidade de Leff (2001) e a discussão levantada por Ball (2012), ao defender que a reforma na educação com base na performatividade e gerencialismo leva à perda da autenticidade, ou seja, a complexidade humana seria reduzida à forma mais simples possível, forçando os profissionais a um reducionismo metodológico e práticas descontextualizadas.

\section{6) Incorporação do multiculturalismo crítico}

No contexto da teoria habermasiana, o mundo da vida teria três componentes estruturantes (cultura, sociedade e personalidade), sendo a cultura entendida como "o acervo de saber a que os atores [sujeitos sociais] recorrem como fonte de interpretações para as mais diversas situações" (REPA, 2008 p.171). Nesse sentido, e considerando a dinâmica globalizada da sociedade, não seria possível a um Estado garantir a sobrevivência de uma determinada cultura, uma vez que os sujeitos, isoladamente ou em grupos sociais, "devem ter a liberdade de decidir sobre quais aspectos de sua própria herança cultural eles querem preservar e de quais se apropriar" (NEVES et al., 2012, p.61). Assim, os sujeitos teriam liberdade de existir em sociedade com determinada cultura, não a preservando porque é importante a existência de múltiplas visões de mundo, mas porque a consideram relevante em suas peculiaridades. Ademais, as diferentes culturas existentes, enquanto 
estruturas dinâmicas e em constante processo de evolução, são interdependentes e influenciam-se mutuamente (MORALES et al., 2012), o que, de certa forma, fomenta justamente o crescimento e o desenvolvimento cultural por si mesmo em seu dinamismo existencial.

Do ponto de vista sociocultural, a cultura é o conjunto de todos os elementos materiais e imateriais construídos pelos seres humanos que caracterizam as peculiaridades de determinada região, grupo ou sociedade. É neste ambiente que surge o conceito de multiculturalismo, que pode ser entendido como o encontro de diversas culturas no mesmo espaço e tempo (KNECHTEL, 2005).

É importante destacar que, no multiculturalismo não há imposição de sentidos, mas negociação permanente. Logo, a educação ambiental que possua um enfoque multicultural auxiliará o sujeito a desenvolver a capacidade de transformar suas próprias diferenças e saberes em expressões de direitos sociopolíticos (MORALES et al., 2012), além de reivindicar um pensar e agir que leve em conta a gestão de conflitos ambientais de forma antissistêmica e anti-hegemônica.

\section{7) Postura ética e cidadã}

A formação dos educadores ambientais deve estar em consonância com os preceitos éticos ${ }^{9}$ existentes, de forma que o sujeito possa aplicar tais conceitos por intermédio do agir de maneira moralmente valiosa. Dessa maneira, possui a função de explicar, esclarecer ou investigar determinada realidade, elaborando os conceitos correspondentes, onde os profissionais trabalhem no campo da discussão teórica sobre os temas apresentados e quanto à postura social frente aos problemas ambientais.

Outro conceito a ser trabalhado pelos educadores ambientais é o de dignidade e de direitos humanos: devem conscientizar os sujeitos de que possuem direitos e deveres em sociedade, e que devem tanto exigir seus direitos como cumprir seus deveres, de forma que haja uma participação ativa do ser na vida social. Radica nesse aspecto a importância de os educadores ambientais, como fontes de tomada de consciência do sujeito para um despertar individual da responsabilidade enquanto membro social.

Nesse sentido, encontra-se o conceito de cidadania, entendida como construção permanente que ocorre ao significar o pertencimento do sujeito em uma sociedade (LOUREIRO; LAYRARGUES; CASTRO, 2002). A cidadania pode ser vista enquanto consciência-reflexão-ação do sujeito, de respeito à vida e de defesa do direito a um meio ambiente equilibrado, considerando que todos vivemos em um único planeta, independente de fronteiras geopolíticas. Destarte, é justamente este o caminho a ser trabalhado pelos educadores ambientais, auxiliando a despertar nos sujeitos suas potencialidades para que possam ser agentes atuantes de transformação do paradigma ambiental existente.

\section{Aproximações com correntes ou perspectivas da Educação Ambiental}

Além dos fundamentos apontados, considera-se que existem correntes de educação ambiental que, ainda que não sejam suficientes por si sós, trazem em seus conceitos

9 Entende-se por ética a teoria ou a ciência do comportamento moral dos homens em sociedade. 
fundamentais posturas, metodologias e abordagens que corroboram a ideia aqui trazida de um educador ambiental mediador de transformações.

Diversos autores propõem sua própria classificação das correntes de educação ambiental. Conforme aponta Sauvé (2005), cada uma das correntes apresenta um conjunto de características específicas que a distingue das outras e, apesar disso, uma corrente pode incorporar proposições que existem em várias correntes diferentes. Sendo assim, optou-se por buscar aquelas que mais se aproximam da visão concebida neste trabalho: a ecoformação e a corrente crítico-reflexiva transformadora, as quais serão explanadas a seguir.

Por ter em seu arcabouço teórico alguns fundamentos considerados aqui como imprescindíveis na formação de educadores ambientais, tais como a abordagem crítica e complexa, buscou-se uma aproximação com a corrente crítico-reflexiva transformadora. A primeira tem característica crítica, de emancipação e práxis, "centrada na aprendizagem, na ação, pela ação e para a ação [...] Implica a ação e a reflexão dos seres humanos sobre o mundo para transformá-lo" (FREIRE, 1997, p.58 apud MORALES, 2007). Nessa dinâmica de reflexão crítico-transformadora é que se vivencia a prática interdisciplinar de construção do conhecimento em educação ambiental. Dessa forma, deve incidir sobre o ser humano e seu meio, o que acarreta numa construção integrada que reflita a realidade e que permita o comprometimento e a compreensão de si mesmo como sujeito histórico e atuante (MORALES, 2007).

Por sua vez, o conceito de ecoformação, à primeira vista, pode ser confundido com a educação ambiental por ser uma das linhas de pensamento desse conceito mais amplo. No entanto, um olhar mais atento nos permite observar algumas diferenças. O termo está presente na literatura a partir da visão de Gaston Pineau, que considera a relação com nós mesmos, com os outros e com o ambiente como etapas inerentes ao processo de formação, constituindo-se, assim, uma auto-hétero-ecoformação ${ }^{10}$ (SILVA, 2008).

A ecoformação traz consigo os preceitos da educação permanente, a qual não pressupõe um fim ou um período determinado em função de sua característica contínua. Direciona sua atuação para uma educação ambiental relacionada ao entorno para o reconhecimento dos elementos essenciais da vida - ar, água, terra e fogo. Tais elementos acompanham o indivíduo do início ao fim da vida e em todas as suas relações, sendo, portanto, permanente. Desse modo, objetivaria a conscientização a respeito do papel exercido pela natureza e seus elementos na constituição e formação do ser humano, a concessão de informações para a elaboração de políticas sustentáveis e uma aproximação aos já mencionados elementos da auto-hétero-ecoformação (SILVA, 2008).

A ecoformação compõe "uma interação entre a educação para o entorno, o desenvolvimento econômico e o progresso social" (NAVARRA, 2008, p. 251-252). Em vez de segregar o indivíduo, o social e o ambiental em compartimentos de importâncias distintas, considera essa relação como complexa e interdependente, propondo uma educação para, no e pelo ambiente (SILVA, 2008).

10 "O homem individualidade (auto) constrói a si mesmo pela interdependência que estabelece com suas alteridades (hétero) e com o ambiente material (eco). Nesse sentido, ao formar-se a si mesmo, o homem também contribuiria para a formação dos outros e do seu ambiente" (SILVA, 2008, p.100). 


\section{Observações finais}

Considerando os fundamentos expostos, averigua-se que os atributos pontuados correspondem a uma revolução na forma de compreender a questão ambiental e de, posteriormente, educar os sujeitos para o enfrentamento da crise socioambiental que se apresenta. Esta proposta de fundamentos e de reflexões que auxiliem na formação de um educador ambiental crítico tem aproximação direta com a corrente crítico-reflexiva transformadora e a concepção de ecoformação.

Afirma-se, também, que os elementos elencados constroem uma visão transformadora da realidade, possibilitando que os sujeitos compreendam a relação sociedade-natureza na sua complexidade e possam agir de forma mais integrada e cidadã diante das problemáticas ambientais que são postas no decorrer de suas vidas. Pondera-se que os educadores ambientais necessitam incorporar em suas práticas, permanentemente, reflexões e aspectos da educação ambiental crítica e mobilizadora, sendo a formação acadêmica ou técnica complementar, mas não inteiramente suficiente para o ato de educar para e sobre o meio ambiente, transformando-o com base em novas atitudes e conhecimentos pertinentes.

É possível dizer, ainda, que a formação de educadores ambientais engloba os diferentes âmbitos da sociedade e não precisa, necessariamente, ser feita por profissionais da educação ou com diplomação específica em meio ambiente. Há fundamentos essenciais para a constituição desse sujeito, que possui papel de imensa responsabilidade diante do quadro de crise no qual a sociedade se encontra.

Educadores ambientais críticos, imbuídos de um embasamento consistente sobre a complexidade e demais características específicas das questões ambientais, podem alterar a realidade desde os sujeitos em idade escolar até aqueles que, informalmente, devem rever sua forma de se relacionar com a natureza. A educação ambiental, transformadora e permanente, requer profissionais que atuem em prol da sustentabilidade do ser individual, do outro e das coisas, atingindo, ainda que de diferentes formas, todos os sujeitos que habitam e dependem deste planeta.

\section{Referências}

ALVARENGA, A.T. de et al.. Histórico, fundamentos filosóficos e teórico-metodológicos da interdisciplinaridade. In: PHILIPPI JR., A.; SILVA NETO, A. J. (Eds). Interdisciplinaridade em ciência, tecnologia \& inovação. Barueri: Manoel, 2011. p.3-69.

BALL, S. Reforma educacional como barbárie social: economicismo e o fim da autenticidade. Tradução: Silvia M. Knechtel Breiby. Práxis Educativa, Ponta Grossa, v.7, n.1, p.33-52, Jan./Jul. 2012. Disponível em:

<http://www.revistas2.uepg.br/index.php/praxiseducativa/article/view/4003/2807>. Acesso em: 20 nov. 2014.

BARCELOS, V. Educação Ambiental - sobre princípios, metodologias e atitudes. 4 ed. Petrópolis: Vozes, 2012. 
Pesquisa em Educação Ambiental, vol. 9, n. 2 - págs. 98-113, 2014

BRASIL. Lei 6.938, de 31 de agosto de 1981. Dispõe sobre a Política Nacional do Meio Ambiente. Disponível em: <http://www.planalto.gov.br/ccivil_03/leis/16938.htm>. Acesso em: 20 nov. 2014.

BRASIL. Casa Civil. Lei 9.394, de 20 de dezembro de 1996. Estabelece as diretrizes e bases da educação nacional. Disponível em: <http://www.planalto.gov.br/ccivil_03/leis/19394.htm>. Acesso em: 20 nov. 2014.

BRASIL. Casa Civil. Lei 9.795, de 27 de abril de 1999. Dispõe sobre Política Nacional de Educação Ambiental. Disponível em: <http://www.planalto.gov.br/ccivil_03/leis/19795.htm>. Acesso em: 20 nov. 2014.

CARNEIRO, S. M. M. et al. Educação ambiental e multiculturalismo: reflexões para a formação de educadores. In: MORALES, A.G. et al. (Orgs.). Educação Ambiental e multiculturalismo. Ponta Grossa: Editora UEPG, 2012. p.79-96.

CARVALHO, I. Educação ambiental: a formação do sujeito ecológico. São Paulo: Cortez, 2008.

DITTRICH, M.G. A criatividade na teoria do corpo-criante: um ponto de partida à transdisciplinaridade e à inovação no ensinar. In: TORRE, S. de la; ZWIEREWIXC, M.; FURLANETTO, E.C. (Orgs.). Formação Docente e Pesquisa Transdisciplinar: criar inovar com outra consciência. Blumenau: Nova Letra, 2011. p.99-122.

FLORIANI, D.; KNECHTEL, M. do R. Educação Ambiental: epistemologia e metodologias. Curitiba: Vicentina, 2003.

FREIRE, A.M.A. O legado de Paulo Freire à educação ambiental. In: NOAL, F.O.; BARCELOS, V. H. de L. (Orgs.). Educação Ambiental e cidadania: cenários brasileiros. Santa Cruz do Sul: EDUNISC, 2003. p.11-21.

KNECHTEL, M. do R. Educação Permanente - da reunificação alemã a reflexões e práticas no Brasil. Curitiba: Editora da UFPR, 2001.

KNECHTEL, M. do R. Multiculturalismo e processos educacionais. Curitiba: Ibpex, 2005.

LEFF, E. Saber ambiental - sustentabilidade, racionalidade, complexidade, poder. Rio de Janeiro: Vozes, 2001.

LOUREIRO, C. F. B.; LAYRARGUES, P. P.; CASTRO, R. S. de. Educação ambiental: repensando o espaço da cidadania. São Paulo: Cortez, 2002.

MORALES, A.G. A formação do profissional educador ambiental: reflexões, possibilidades e constatações no curso de especialização da UFPR. 2007. 233p. Tese (Doutorado em Meio Ambiente e Desenvolvimento) - Universidade Federal do Paraná. Curitiba, 2007.

MORALES, A.G. A formação do profissional educador ambiental - Reflexões, possibilidades e constatações. Ponta Grossa: Editora da UEPG, 2012.

MORALES, A.G. et al. (Orgs.). Educação Ambiental e multiculturalismo. Ponta Grossa: Editora UEPG, 2012. 
Pesquisa em Educação Ambiental, vol. 9, n. 2 - págs. 98-113, 2014

MORIN, E. Introdução ao pensamento complexo. Porto Alegre: Editora Sulina, 2011.

NAVARRA, J.M. Ecoformação- além da educação ambiental. In: TORRE, S. de la; PUJOL, M. A.; MORAES, M. C. Transdisciplinaridade e ecoformação: um novo olhar sobre a educação. São Paulo: TRIOM, 2008. p.235-260.

NEVES, F. M. et al. Multiculturalismo, educação ambiental e processos sociais. In: MORALES, A.G. et al. (Orgs.). Educação Ambiental e multiculturalismo. Ponta Grossa: Editora UEPG, 2012. p.57-78.

OLIVEIRA, H.T. de. Transdisciplinaridade. In: FERRARO JÚNIOR, L. A. (Org.). Encontros $e$ caminhos: formação de educadoras (es) ambientais e coletivos educadores. Brasília: MMA, Diretoria de Educação Ambiental, 2005. p.335-343.

ORGANIZAÇÃO DAS NAÇÕES UNIDAS - ONU. Declaração de Estocolmo sobre meio ambiente humano. Biblioteca virtual de Direitos Humanos, Universidade de São Paulo. Disponível em: <http://www.direitoshumanos.usp.br/index.php/Meio-Ambiente/declaracao-de-estocolmosobre-o-ambiente-humano.html>. Acesso em: 20 nov. 2014.

RAYNAUT, C.; ZANONI, M. Reflexões sobre princípios de uma prática interdisciplinar na pesquisa e no ensino superior. In: PHILIPPI JR., A.; SILVA NETO, A. J. (Eds).

Interdisciplinaridade em ciência, tecnologia \& inovação. Barueri: Manoel, 2011. p.143-208.

REIGOTA, M. O que é Educação Ambiental. São Paulo: Brasiliense, 2001.

REPA, L. Jürgen Habermas e o modelo reconstrutivo de teoria crítica. In: NOBRE, M. (Org.). Curso livre de Teoria Crítica. Campinas: Papirus, 2008. p. 161-182.

SILVA, A.T.R. O campo epistemológico da educação ambiental: o dualismo homem/natureza e o paradigma da complexidade. 2007. 301p. Tese (Doutorado em Meio Ambiente e Desenvolvimento) - Universidade Federal do Paraná. Curitiba, 2007.

SILVA, A.T.R. Ecoformação: reflexões para uma pedagogia ambiental, a partir de Rousseau, Morin e Pineau. Desenvolvimento e Meio Ambiente, Curitiba, v. 18, n.18, p. 95-104, Jul./Dez., 2008.

SALES, T.B.; CANTARINO, A. Educação Ambiental empresarial como ferramenta na gestão ambiental. In: CONGRESSO NACIONAL DE GESTÃO EMPRESARIAL, 7, Rio de Janeiro, 2011. Anais... Rio de Janeiro: FIRJAN, 2011. p.1-22. Disponível em:

<http://www.excelenciaemgestao.org/Portals/2/documents/cneg7/anais/T11_0352_2183.pdf>. Acesso em: 20 nov. 2014.

SAUVÉ, L. Uma cartografia das correntes em educação ambiental. In: SATO, M.; CARVALHO, I. (Org.). Educação ambiental: pesquisa e desafios. Porto Alegre: Artmed, 2005. p.17-44.

SOUZA-LIMA, J. E. de; KNECHTEL, M. do R. Multiculturalismo e educação ambiental: dois campos de coexistência das racionalidades culturais e ambientais. In: MORALES, A.G. et al. (Orgs.). Educação Ambiental e multiculturalismo. Ponta Grossa: Editora UEPG, 2012. 
TORRE, S. de la. Cómo innovar en los centros educativos - Estudio de casos. Madrid: Escuela Española, S.A.,1998.

UNITED NATIONS FOR THE EDUCATION, SCIENCE AND CULTURE. UNESCO. $\mathrm{La}$ Educación Ambiental: las grandes orientaciones de la Conferencia de Tbilisi. Vendome: Presses Universitaires de France, 1980.

Artigo recebido em 13/11/2013

Aceite em 25/08/2014 